\title{
Comparison of efficacy of visual inspection with $4 \%$ acetic acid, visual inspection with Lugol's iodine, Pap smear and colposcopy in screening cervical precancerous lesions
}

\author{
Apurba K. Bhattacharya, Hem K. Sarma, Antara Das*
}

Department of Obstetrics and Gynaecology, Jorhat Medical College and Hospital, Jorhat, Assam, India

Received: 26 November 2021

Accepted: 28 December 2021

\section{*Correspondence:}

Dr. Antara Das,

E-mail: antaradas742ad.76@gmail.com

Copyright: (C) the author(s), publisher and licensee Medip Academy. This is an open-access article distributed under the terms of the Creative Commons Attribution Non-Commercial License, which permits unrestricted non-commercial use, distribution, and reproduction in any medium, provided the original work is properly cited.

\section{ABSTRACT}

Background: Cervical malignancy is the fourth most common cancer in women worldwide. Screening of high-grade cervical intraepithelial neoplasia aids in early detection and their effective treatment which constitutes the most effective and widely used strategy to prevent cervical carcinoma throughout the world. Objectives of the study were to: screen women with visual inspection with $4 \%$ acetic acid (VIA), visual inspection with Lugol's iodine (VILI), Pap smear and colposcopy who have abnormal symptoms for unhealthy cervix; and to evaluate the sensitivity and specificity of VIA, VILI, Pap smear and colposcopy.

Methods: This was a hospital based cross sectional study conducted at Jorhat Medical College, Assam at the department of obstetrics and gynaecology from June 2020 to May 2021, carried out on 60 women. This study was done on 60 women who fulfilled the inclusion and exclusion criteria, were first subjected to Pap smear followed by VIA, VILI, colposcopy and biopsy for confirmation of lesion, if needed. Data was obtained and statistically analyzed.

Results: VIA showed sensitivity $96.15 \%$, specificity $62.50 \%$ and diagnostic accuracy $88.23 \%$. VILI showed sensitivity $89.65 \%$, specificity $40 \%$ and diagnostic accuracy $82.35 \%$. Colposcopy showed sensitivity $96.66 \%$, specificity $25 \%$ and diagnostic accuracy $88.23 \%$. Pap smear showed sensitivity of $86.66 \%$, specificity $75 \%$ and diagnostic accuracy of $85.29 \%$.

Conclusions: Our study shows that VIA, VILI, Pap smear and colposcopy has comparable sensitivity. Pap smear shows better specificity. Therefore, use of combination of these tests gives better sensitivity and specificity for early detection of cervical carcinoma.

Keywords: Cervical cancer, Pap smear, Visual inspection with acetic acid, Visual inspection with Lugol's iodine, Colposcopy

\section{INTRODUCTION}

Cervical malignancy is the fourth most common cancer in women worldwide. Screening of high-grade cervical intraepithelial neoplasia aids in early detection and their effective treatment which constitutes the most effective and widely used strategy to prevent cervical carcinoma throughout the world.
In 2020, GLOBACAN estimated 123,907 incident cases and 77,348 deaths, with an age-standardized incidence rate of 18 per 100,000 women and a cumulative risk of $2.01 \%{ }^{1}$

In India, it is estimated that there are 96,922 new cervical cancer cases $(9.2 \%)$ with an age-standardized incidence rate of $14.7 / 10^{5}$ (higher than the rates observed in many other countries across the globe) and 60,078 cervical cancer deaths $(8.4 \%)$ with a mortality rate of $9.2 / 10^{5} .^{2}$ 
The continuing high risk and burden of cervical cancer in developing countries is due to the difficulties in providing optimal cytology screening with inadequate coverage for both testing and treatment of precursor lesions or lack of screening. ${ }^{3-6}$

The need for affordable and accurate alternative tests for use in low-resource health services has led to the increasing use of naked eye visual inspection methods relying on visible changes on the cervix following the application of $4-5 \%$ acetic acid (VIA) or Lugol's iodine (VILI) to screen for cervical lesions. Newer approaches such as automated Pap, liquid-based Pap and human papillomavirus deoxyribonucleic acid (HPV DNA) testing using hybrid capture II (HC II) are time consuming, expensive and not widely available. Prompted by the need for optimal strategies for cervical cancer screening in lowresource settings, the role of visual inspection with acetic acid (VIA) and visual inspection with Lugol's iodine (VILI) has been widely studied in several recent studies, which suggest that VIA and VILI closely match the Pap smear in its performance in detecting cervical cancer precursor. $^{7}$

\section{METHODS}

The present study was carried out in the department of obstetrics and gynaecology at Jorhat Medical College and Hospital, Jorhat, for a period of 1 year (June 2020 to May 2021). A total of 60 patients attending the gynaecology outpatient department (OPD) were enrolled in the study. Pertinent history relating to age, age of marriage (proxy for coitarche), parity, contraceptive use, socio-economic status, predominant symptoms and sexual history were recorded on a computer generated proforma for each woman.

\section{Inclusion criteria}

Women of age group 21-60 years; and all women after the age of 20 or earlier if sexually active were included.

\section{Exclusion criteria}

Noncompliance of patients and those who refrain from giving consent; active bleeding per vagina; profuse cervical and vaginal discharge; obvious cervical growth; history of hysterectomy; surgical treatment of the cervix; iodine allergy; pregnant patient wanting continuation of pregnancy; and with history of cervical neoplasia were excluded.

\section{Procedure}

Patients to be screened were explained the procedure to be performed, written informed consent was taken and the relevant obstetrical and gynaecological history was also taken, with the patient being reassured that the procedure was painless. All the patients in the study were subjected to colposcopy. The cervix was inspected with naked eye then with a colposcope. Firstly, a Pap smear was taken with Ayre's spatula and cytobrush and was evaluated by the Bethesda system. Following Pap smear, the cervix was washed with normal saline and visualized, then VIA was performed with $5 \%$ acetic acid followed by VILI and visualized by colposcope. Grading of lesion was done according to the Reid's colposcopic index. Biopsy was done for confirmation of lesion if either of the screening tests or colposcopy had a positive finding or if the Pap smear reported ASCUS, for confirmation of lesion. Collected data was statistically analyzed to determine specificity and sensitivity, positive predictive value (PPV), negative predictive value (NPV) and diagnostic accuracy of VIA plus VILI plus Pap smear plus colposcopy. Approval from ethical committee of our institute was taken before commencing the study.

\section{RESULTS}

Out of 60 patients enrolled for the study, $33 \%$ were in the age group of $31-40$ years, $36 \%$ belonged to socioeconomic grade $4,58 \%$ had menarche at the age of $12-13$ years, $51 \%$ were married at the 19-21 years, $43 \%$ had parity 2 with multiple episodes of abortion and majority women (40\%) did not use any method of contraception in their life. Most women came with chief complaint of white vaginal discharge (35\%). After taking detailed history, patients were subjected to VIA, VILI, Pap smear and colposcopy and findings were recorded and analysed. Biopsy was taken in 34 patients with positive Pap smear and colposcopy findings and correlated accordingly.

On colposcopy, $38.33 \%$ women showed inflammatory changes, $16.66 \%$ showed mild to moderate aceto-white areas, $1.66 \%$ showed punctate pattern, mosaic pattern and atypical vessels respectively. $1.66 \%$ showed unsatisfactory result (Table 1).

Table 1: Distribution of study population according to colposcopy findings.

\begin{tabular}{|lll|}
\hline $\begin{array}{l}\text { Colposcopic } \\
\text { appearance }\end{array}$ & Frequency & $\begin{array}{l}\text { Percentage } \\
(\%)\end{array}$ \\
\hline Normal & 18 & 30 \\
\hline Cervical erosion & 5 & 8.33 \\
\hline Inflammatory changes & 23 & 38.33 \\
\hline Polyp & - & - \\
\hline Leukoplakia & - & - \\
\hline Aceto-white areas & 10 & 16.66 \\
\hline Punctate pattern & 1 & 1.66 \\
\hline Mosaic pattern & 1 & 1.66 \\
\hline Atypical vessels & 1 & 1.66 \\
\hline Unsatisfactory & 1 & 1.66 \\
\hline
\end{tabular}

Amongst 60 women, 43 women (71.66\%) were VIA positive, 17 women $(28.33 \%)$ were VIA negative, 39 women $(65 \%)$ were VILI positive and 21 women $(35 \%)$ were VILI negative (Table 2). 
Table 2: Distribution of study population according to VIA and VILI result.

\begin{tabular}{|lll|}
\hline Test & No. of cases & $\begin{array}{l}\text { Percentage } \\
(\%)\end{array}$ \\
\hline Via positive & 43 & 71.66 \\
\hline Via negative & 17 & 28.33 \\
\hline Total & 60 & 100 \\
\hline VILI positive & 39 & 65 \\
\hline VILI negative & 21 & 35 \\
\hline Total & 60 & 100 \\
\hline
\end{tabular}

Pap smear taken on 60 women, 55\% showed normal cervix, $40 \%$ showed inflammatory changes and 1 woman $(1.66 \%)$ showed mild dysplasia, moderate dysplasia and invasive carcinoma respectively (Table 3 ).

Out of 34 women, 22 women (VIA+) had inflammatory changes in biopsy. 1 woman (VIA+) showed mild dysplasia, moderate dysplasia and invasive carcinoma respectively. 3 women (VIA+) showed no major lesion in biopsy and 5 women (VIA-) showed no major lesion in biopsy (Figure 1).

Out of 34 women, 23 women (VILI+) had inflammatory changes in biopsy. 3 women (VILI-) had inflammatory changes in biopsy. 1 woman (VILI+) showed mild dysplasia, moderate dysplasia and invasive carcinoma respectively. 3 women (VILI+) showed no major lesion in biopsy and 2 women (VILI-) showed no major lesion in biopsy (Figure 2).
Out of 34 women, 14 women had inflammatory changes in colposcopy and biopsy. 5 women (cervical erosion on colposcopy) showed inflammatory changes in biopsy. Out of the 10 cases showing acetowhite epithelium in colposcopy, 7 women had inflammatory changes in biopsy and 3 women had no lesion in biopsy. 1 woman with punctate pattern of vessels had mild dysplasia. 1 woman with mosaic pattern of vessels had moderate dysplasia in biopsy and 1 woman with atypical vessels showed invasive carcinoma in biopsy (cancer cervix stage III). 2 women had unsatisfactory colposcopy, 1 of them showed inflammatory changes in biopsy (Figure 3).

Table 3: Distribution study population according of Pap smear finding.

\begin{tabular}{|lll|}
\hline Pap smear findings & No. of cases & $\begin{array}{l}\text { Percentage } \\
(\%)\end{array}$ \\
\hline Normal & 33 & 55 \\
\hline Inflammatory atypia & 24 & 40 \\
\hline Mild dysplasia & 1 & 1.67 \\
\hline Moderate dysplasia & 1 & 1.67 \\
\hline Severe dysplasia & 0 & 0 \\
\hline Invasive cancer & 1 & 1.66 \\
\hline
\end{tabular}

Out of 34 women, 23 women with inflammatory changes in both Pap smear and biopsy. 1 woman showed CIN 1, CIN 2 and invasive carcinoma respectively (both Pap smear and colposcopy). 4 women with inflammatory changes in Pap smear showed no lesion in biopsy (Figure 4). Test characteristics of screening tests in detecting CIN (Table 4).

Table 4: Test characteristics of screening tests in detecting CIN.

\begin{tabular}{|llllllllll|}
\hline Test & $\begin{array}{l}\text { True } \\
\text { posit- } \\
\text { ive }\end{array}$ & $\begin{array}{l}\text { True } \\
\text { negative }\end{array}$ & $\begin{array}{l}\text { False } \\
\text { positive }\end{array}$ & $\begin{array}{l}\text { False } \\
\text { negative }\end{array}$ & $\begin{array}{l}\text { Sensitivity } \\
(\%)\end{array}$ & $\begin{array}{l}\text { Specificity } \\
(\%)\end{array}$ & $\begin{array}{l}\text { PPV } \\
(\%)\end{array}$ & $\begin{array}{l}\text { NPV } \\
(\%)\end{array}$ & $\begin{array}{l}\text { Diagnostic } \\
\text { accuracy } \\
(\%)\end{array}$ \\
\hline VIA & 25 & 5 & 3 & 1 & 96.15 & 62.50 & 89.28 & 83.33 & 88.23 \\
\hline VILI & 26 & 2 & 3 & 3 & 89.65 & 40 & 89.65 & 40 & 82.35 \\
\hline Colposcopy & 29 & 1 & 3 & 1 & 96.66 & 25 & 93.54 & 50 & 88.23 \\
\hline Pap smear & 26 & 3 & 1 & 4 & 86.66 & 75 & 96.29 & 42.85 & 85.29 \\
\hline
\end{tabular}

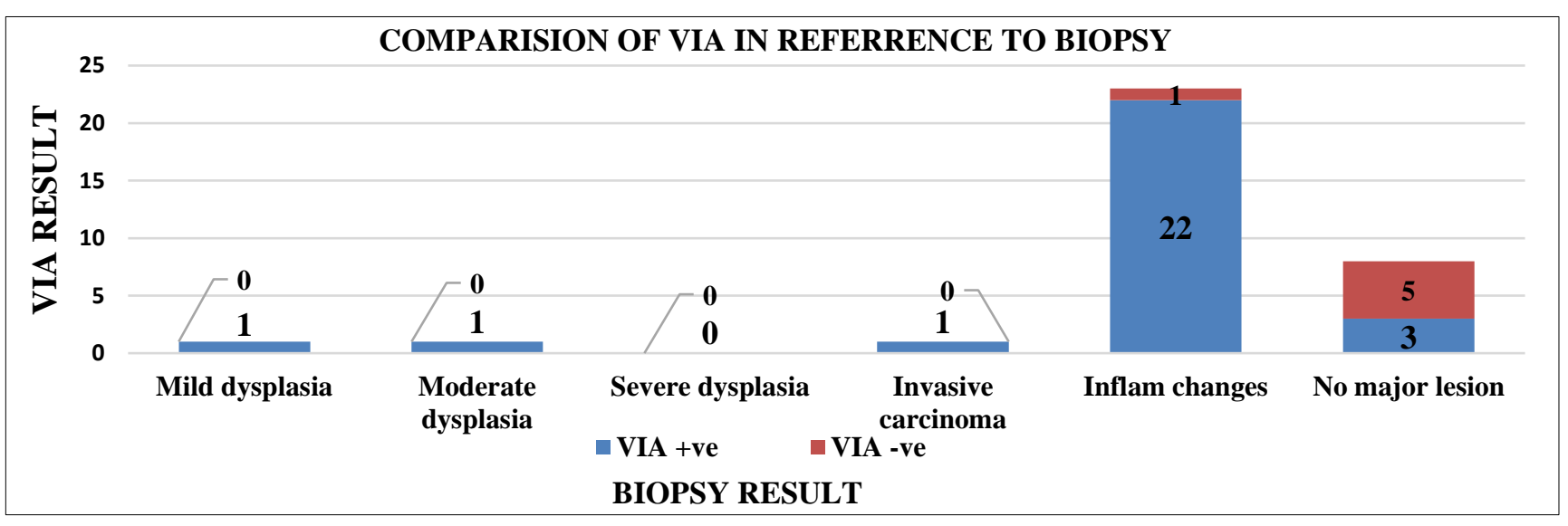

Figure 1: Correlation of VIA with biopsy findings. 


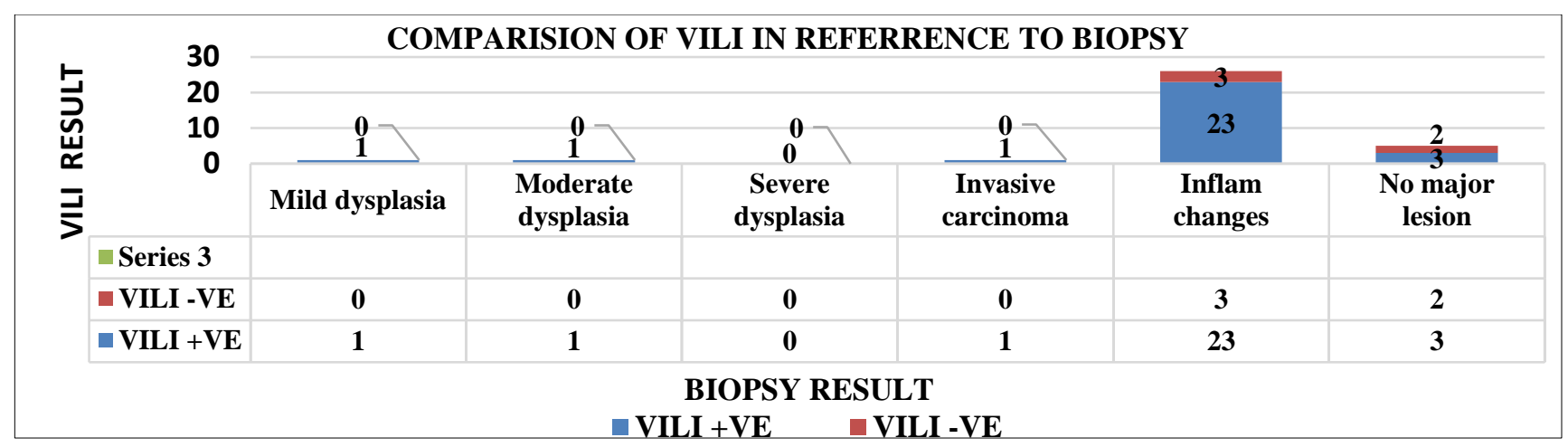

Figure 2: Correlation of VILI with biopsy findings.

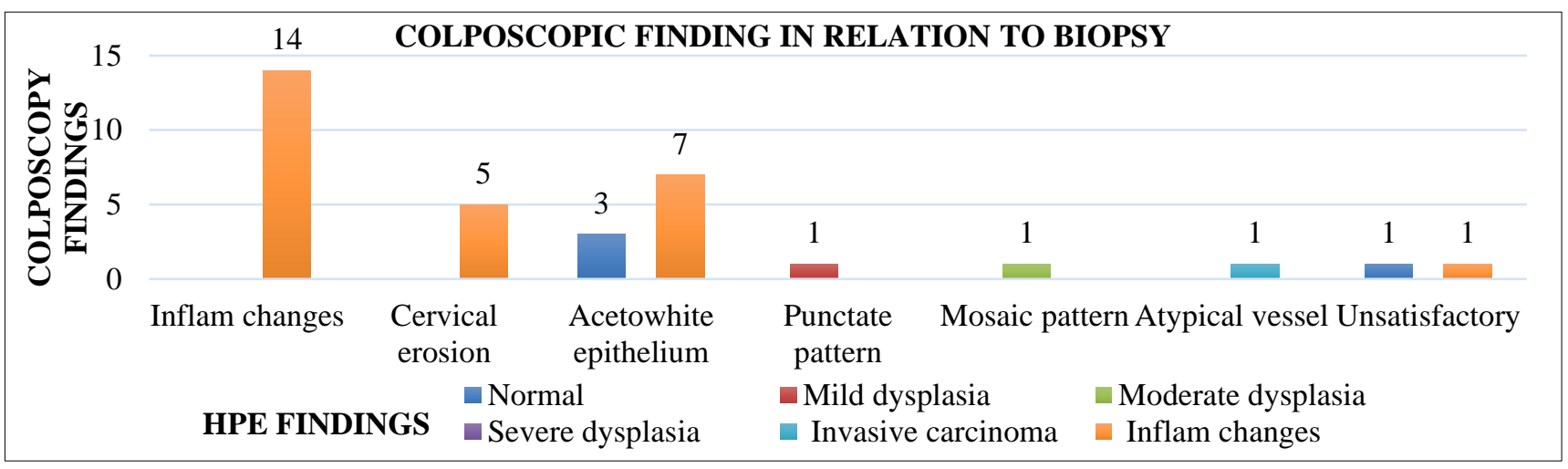

Figure 3: Correlation of colposcopy finding with biopsy findings.

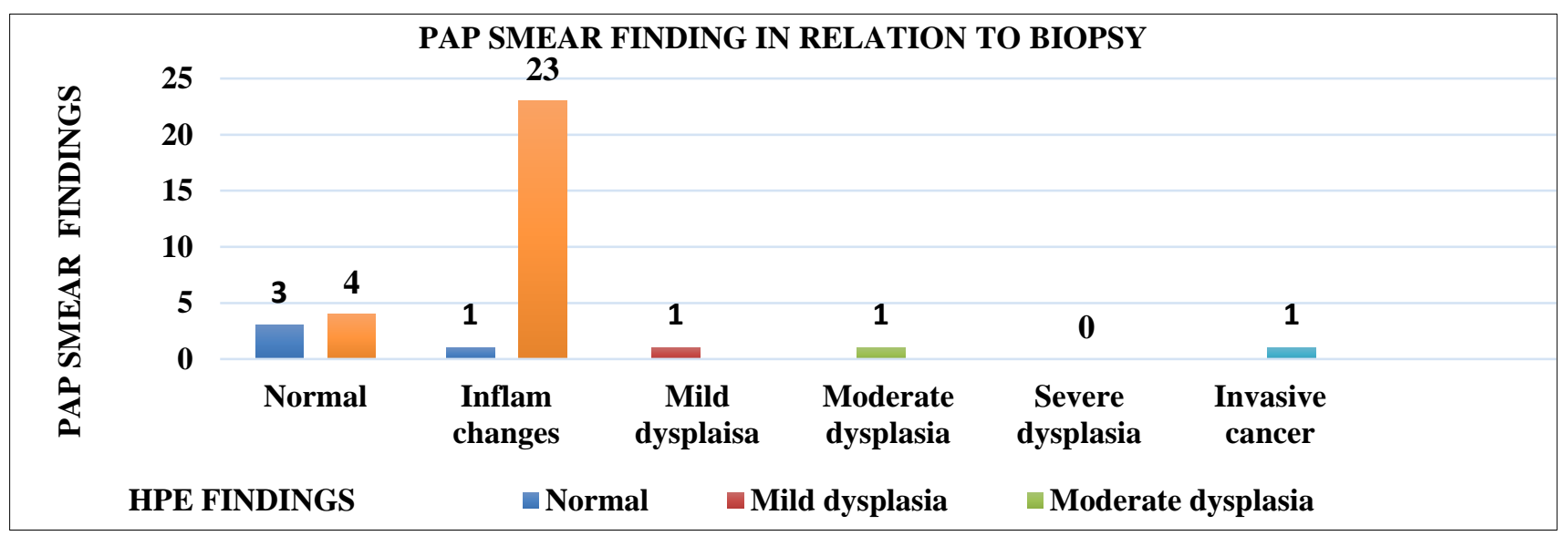

Figure 4: Correlation of Pap smear with biopsy findings.

\section{DISCUSSION}

Though cervical cancer can be detected in the earlier treatable stages, the morbidity and mortality due to cervical cancer is not reducing because of the failure of the cervical cancer screening programs especially in the developing world. Organized and frequently repeated cytology screening has resulted in a substantial reduction of cervical cancer burden in developed countries. But in low-resource countries, VIA-based approaches have been successfully tested and proposed to address the need to effectively improve and extend screening services in the country. 8,9
In the present study, we found 1 case of CIN 1, CIN 2 and invasive carcinoma and efficacy of various screening methods used in this study were compared with other studies. Sensitivity, specificity of VIA/VILI of our study finding is consistent with that of Manisha et al, Goyal et al, Ardahan et al, and Savitha et al. ${ }^{10-13}$

In this study, VIA showed higher sensitivity (96.15\%) but low specificity $(62.50 \%)$. The reason behind the high sensitivity and/or low specificity of VIA in our study could be due to: presence of infection and inflammation that take up acetowhite stain; some faint acetowhite areas might 
have been interpreted as being positive; and scoring those areas with distinct acetowhite uptake on cervix as positive.

Because of the high number of false-positive cases and low specificity of VIA, the usefulness of this procedure is limited. But, due to the high sensitivity of VIA, it is still used as primary screening in some developing countries for early detection of cervical carcinoma.

In the present study, VILI showed lower sensitivity $(89.65 \%)$ and specificity $(40 \%)$ than VIA.

Mild discrepancy of diagnostic accuracy was seen on comparison with other studies, due to difference in sample size along location and duration of the study (Table 5).
Pap smear had higher specificity (75\%) than VIA, VILI, colposcopy, but with almost similar diagnostic accuracy. Therefore, in our setting, we can use combined VIA, VILI. Colposcopy and Pap smear for screening of cervical precancerous lesion, as combined they give much higher diagnostic accuracy.

Although our present study shows better diagnostic accuracy of the test methods applied (VIA+VILI+colposcopy+Pap smear), several limitations were there. Limitations being small sample size, shorter duration of study, testing patients only coming to gynaecology OPD of Jorhat Medical College instead of the all the women in the remote areas of villages where accessibility of health care facility is far from reach.

Table 5: Comparison of diagnostic accuracy of colposcopy and Pap smear with other studies.

\begin{tabular}{|c|c|c|c|}
\hline Study & $\begin{array}{l}\text { Diagnostic accuracy of } \\
\text { colposcopy }(\%)\end{array}$ & Study & $\begin{array}{l}\text { Diagnostic accuracy of Pap } \\
\text { smear }(\%)\end{array}$ \\
\hline Present study & 88.23 & Present study & 85.29 \\
\hline Olaniyan et al ${ }^{14}$ & 80.0 & Shalini et al $^{16}$ & 81 \\
\hline Massad et al ${ }^{15}$ & 86.0 & Savitha et al ${ }^{13}$ & 82 \\
\hline Savitha et al ${ }^{13}$ & 85.0 & Ashmita et al ${ }^{17}$ & 86.54 \\
\hline
\end{tabular}

Women continue to ignore symptoms of irregular bleeding, postmenopausal bleeding and postcoital bleeding.

Therefore, in our study, we aimed at educating women about these signs and symptoms and to seek immediate medical care.

Thus, an attempt has been made to target the disease before its onset at the level of primary prevention by providing education and counselling and secondary prevention by effective screening and treatment.

\section{CONCLUSION}

Cervical cancer is "preventable but not prevented" remains the reality today, because no perfect screening tests are available that have $100 \%$ sensitivity and good specificity. We can develop a cost- effective screening method by training medical and paramedical staff stating from primary health centre level up to the highest level. Therefore, in the present study, an attempt has been made to analyze Pap smear, VIA and VILI and colposcopy in combination for early detection cervical precancerous lesion.

Therefore, from our present study, we recommend a combined approach involving VIA, VILI, colposcopy and Pap smear for early detection of CIN and cervical carcinoma. Awareness should be created regarding HPV infection and its association with cervical carcinoma. Test for HPV infection should be done and HPV vaccination should be recommended where resources are available to reduce the incidence of cervical carcinoma.

\section{ACKNOWLEDGMENTS}

Authors would like to thank all the women and their family members for their co-operation. They would also like to thank all the working members of department of obstetrics and gynaecology for their inputs in patient care.

Funding: No funding sources

Conflict of interest: None declared

Ethical approval: The study was approved by the Institutional Ethics Committee

\section{REFERENCES}

1. Sung H, Ferlay J, Siegel RL, Laversanne M, Soerjomataram I, Jemal A, et al. Global Cancer Statistics 2020: GLOBOCAN Estimates of Incidence and Mortality Worldwide for 36 Cancers in 185 Countries. CA Cancer J Clin. 2021;71(3):209-49.

2. Global Cancer Data: GLOBOCAN 2018 | UICC. Available at: https://www.uicc.org/news/globalcancer-data-globocan-2018. Accessed on 05 September 2021.

3. Sankaranarayanan R, Budukh AM, Rajkumar R. Effective screening programmes for cervical cancer in low- and middle-income developing countries. Bull World Health Organ. 2001;79(10):954-62.

4. World Health Organization. IARC Handbooks of Cancer Prevention on Cervix Cancer Screening. Volume 10. Lyon. IARC press. 2005.

5. Ferlay J, Shin H-R, Bray F, Forman D, Mathers C, Parkin DM. Estimates of worldwide burden of cancer in 2008: GLOBOCAN 2008. Int $\mathbf{J}$ Cancer. 2010;127(12):2893-917. 
6. Denny L, Kuhn L, Hu C-C, Tsai W-Y, Wright TC. Human papillomavirus-based cervical cancer prevention: long-term results of a randomized screening trial. J Natl Cancer Inst. 2010;102(20):1557-67.

7. Sankaranarayanan R, Wesley R, Thara S, Dhakad N, Chandralekha B, Sebastian P, et al. Test characteristics of visual inspection with $4 \%$ acetic acid (VIA) and Lugol's iodine (VILI) in cervical cancer screening in Kerala, India. Int $\mathrm{J}$ Cancer. 2003;106(3):404-8.

8. Schiffman M. Solomon D. Findings to date from the ASCUS-LSIL Triage Study (ALTS). Arch Pathol Lab Med. 2003;127:946-9.

9. Sheshadri V, O'Connor DM. The agreement of colposcopic grading as compared to directed biopsy results. J Low Genit Tract Dis. 1999;3:150-4.

10. Manisha S, Bagde N, Shrivastava D. Visual inspection of cervix with acetic acid: An alternative to cytology and colposcopy in early screening of cervical cancer in low-resource setup. J Datta Meghe Inst Med Sci Univ. 2017;12:32-4.

11. Goyal S, Tandon P, Bhutani N, Gill BK. To study the role of visual inspection of cervix with acetic acid (VIA) in cervical cancer screening. Int J Reprod Contracept Obstet Gynecol. 2017;3(3):684-7.

12. Ardahan M, Temel AB. Visual inspection with acetic acid in cervical cancer screening. Cancer Nurs. 2011 Apr;34(2):158-63.

13. Savitha TS, Sapna W. A comparison of PAP smear, colposcopy and colposcopy directed biopsy in evaluation of unhealthy cervix. J Evolution Med Dent Sci. 2015;4(21):3639-47.

14. Olaniyan OB. Validity of colposcopy in the diagnosis of early cervical neoplasia--a review. Afr J Reprod Health. 2002;6(3):59-69.

15. Massad LS, Jeronimo J, Katki HA, Schiffman M, National Institutes of Health/American Society for Colposcopy and Cervical Pathology Research Group. The accuracy of colposcopic grading for detection of high-grade cervical intraepithelial neoplasia. J Low Genit Tract Dis. 2009;13(3):137-44.

16. Shalini R, Amita S, Neera MA. How alarming is postcoital bleeding--a cytologic, colposcopic and histopathologic evaluation. Gynecol Obstet Invest. 1998;45(3):205-8.

17. Ashmita D, Shakuntala PN, Rao SR, Sharma SK, Geethanjali S. Comparison and Correlation of PAP smear, Colposcopy and Histopathology in Symptomatic Women and Suspicious Looking Cervix in a Tertiary Hospital Care Centre. Int J Health Sci Res. 2013;3(5):50-9.

Cite this article as: Bhattacharya AK, Sarma HK, Das A. Comparison of efficacy of visual inspection with $4 \%$ acetic acid, visual inspection with Lugol's iodine, Pap smear and colposcopy in screening cervical precancerous lesions. Int J Reprod Contracept Obstet Gynecol 2022;11:449-54. 